\title{
Accounting
}

\section{Factors affecting the role of women in the economic development of rural household families in Vietnam: A case study in Trieu Son district Thanh Hoa province}

\author{
Doan Van Truonga*, Nguyen Giao ${ }^{\mathrm{b}}$ and Le Thi Thuy Ly ${ }^{\mathrm{b}}$
}

\begin{tabular}{l} 
Article history: \\
Received February 22019 \\
Received in revised format \\
February 272020 \\
Accepted March 12020 \\
Available online \\
March 1 2020 \\
\hline Keywords: \\
Women \\
Household family \\
Rural \\
Role \\
Vietnam
\end{tabular} \\ Article history:
}

${ }^{a}$ Thanh Hoa University of Culture, Sports and Tourism, Vietnam

${ }^{b}$ Institute of Cultural Studies, Vietnam Academy of Social Sciences, Vietnam

\section{A B S T R A C T}

\begin{abstract}
This study aims to analyze the factors affecting the role of women in the economic development of rural household families in Vietnam. 210 survey samples collected in Trieu Son district, Thanh Hoa province were used as data in the study. The study finds a number of important factors influencing the role of women in rural household economic development. Since then, some meaningful solutions to promote the role of women in the economic development of rural household families in Trieu Son district are proposed in the study.
\end{abstract}

\section{Introduction}

In Vietnam, women make up over $50 \%$ of the country's population. They participate in economy, politics, culture, society, security and national defense and increasingly prove their role in society. In the cause of national renewal, women always uphold and promote the spirit of patriotism, solidarity, dynamism and creativity. They are always ready to overcome all difficulties in studying and labor for the hope of achieving outstanding achievements in all fields. Trieu Son district is a midland region of Thanh Hoa province, Vietnam. Today, it is home to $50.5 \%$ of the female population (Trieu Son, 2011). They have made great contributions to the socio-economic development of the district. However, the contribution of women has not been recognized in a commensurate way with their role in the economy, social relations and family life. Especially, in a market economy, women must both have to do well in social work and take on the role of a wife and a mother in spite of their limited time and weak health. In order to perform well the duties in the family and society, they must make efforts and sacrifice, but their interests in all aspects have not been paid enough attention. Therefore, it is necessary to study the factors affecting the role of women in the economic development of rural household families in Trieu Son district, Thanh Hoa province. From there, a number of feasible solutions need to be proposed in order to further promote the role of women in the construction of rural areas in particular and the development of Vietnam in general.

\footnotetext{
* Corresponding author.

E-mail address: dvtruongxhh@gmail.com (D.V. Truong)
} 


\section{Literature Review}

There have been many published researches on women's role in economic development. During the 1980s, the first studies on this issue appeared (Beneria, 1981; Baarhmitash, 2000; Basu \& Basu,1991). In Africa, in the 1980s, the history of women has evolved into an important area and continues to be further studied due to the development of the international feminist movement (Bayeh, 2016). In the $70 \mathrm{~s}$ of the $20^{\text {th }}$ century, until the beginning of the $21^{\text {st }}$ century, there were a number of important researches on women accomplished. In Vietnam, studies conducted by Quyen and Nguyen (2006) show that women have less time to relax after working hard. Women have to averagely work 11.2 hours per day, accounting for $46.8 \%$ of the total amount of time. Even in the busiest time, they have to work 18 hours a day, accounting for $75 \%$ of the total amount of time. Also, in the idlest time, women work 8 hours a day, accounting for $25 \%$ of the total amount of time (Quyen \& Nguyen, 2006; Fabiyi, 2007). Nguyen Ngoc Quynh (2009) stated that the female labor force in agriculture is quite abundant, accounting for $52 \%$ of the labor force in agriculture. Most of women are the main labor in the family because they directly engaged in production and earned income for the whole family (Quynh, 2009). Vuong Thi Van (2009) stated that there is an inequality between men and women in participating in community activities. More than $46.4 \%$ of husbands attend village local common activities to acquire knowledge about policies and laws. This further widens the gap in awareness and social understanding between men and women (Van, 2009). It can be seen that the role of women is of great interest to many researchers, especially those related to and directly identifying factors affecting women's roles in the economic development of rural household families. Thus, it is essential for us to perform practical policies and solutions to ensure fairness of rights, roles and responsibilities between women and men (Boserup, 1970).

\section{Model and research methodology}

\subsection{Model and research hypothesis}

In this study, we used Pearson correlation coefficient, Binary Logistic regression model, Cronbach Alpha to analyze the correlation between 5 factors and the hypothesis test as follows:

$\mathrm{H}_{0}$ : There is no relationship between variables.

$\mathrm{H}_{1,2,3,4,5}$ : There is a relationship between variables.

The study is based on $\mathrm{p}\left(\mathrm{p}\right.$-value) and depends on certain confidence level $(\mathrm{p}<0.05)$ to accept or reject the null hypothesis $\mathrm{H}_{0}$. To study their impact on the role of women in the economic development of rural household families, we have selected 5 groups of factors including social policy (SP); Education (E); Gender inequality (GI); Health (H); Accessibility to Information (AI). In which, (SP) includes mechanisms and policies, laws of the Party and State and of local authorities; (E) includes Illiteracy, elementary school level, high school level, immediate level, tertiary education level and postgraduate level; (GI) includes Awareness of women's role, the inequality of production activities; $(\mathrm{H})$ includes physical health and mental health; (AI) includes women's participation in training programs, community activities, access to social resources and social policies (banks for social polies, mass and social organizations). There are 5 main factors (SP, E, GI, H, AI,) with the hypotheses as follows:

$\mathrm{H}_{1}$ : Social policies directly affect women's role in the economic development of household families.

$\mathrm{H}_{2}$ : Low education limits women's role in the economic development of household families.

$\mathrm{H}_{3}$ : Gender inequality hinders women's role in the economic development of household families nowadays.

$\mathrm{H}_{4}$ : Health is an important factor affecting women's role in the economic development of household families.

$\mathrm{H}_{5}$ : Low accessibility to information directly affects women's role in the economic development.

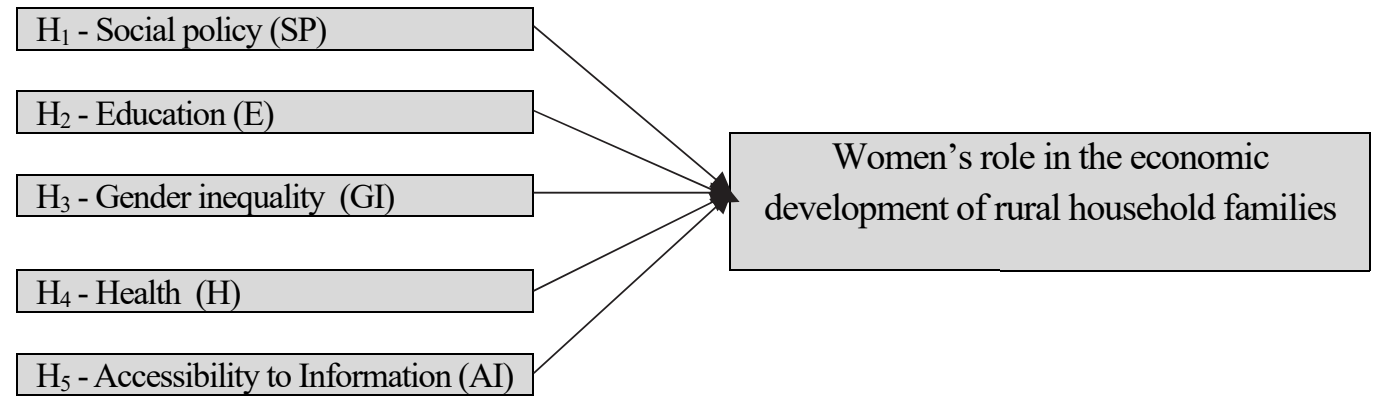

Fig.1. Research model

(Source: Synthesis of author) 


\subsection{Description of the data}

(i) The main objective of the study was on women involved in the economic development of rural household families. In addition, men were selected as the second participants whose assessments provide a basis for further identification of factors affecting women's role in the economic development of household families.

(ii) The authors chose a clustered non-probability sampling method that is divided into several stages. This is considered to be an effective, inexpensive and time-consuming method of collecting information quickly. We use each interviewee to record the answers on the data collection form. The sample structure was selected based on age, gender, education, occupation, ethnicity and living conditions of each household family.

(iii) To gain the research purpose, 210 representative samples corresponding to 210 women and men participating in production activities and household economic development were selected to clarify and collect information. To analyze elements and regression of binary logit, the sample scale was multiplied at least 5 times by the number of questions (Ba et al., 2020). The study was designed with a total of 40 questions corresponding to at least 200 samples. However, in case of a household family could not be found or they refused to answer the questions, the authors tooked at 10 additional backup samples from the same sampling list. In this way, the necessary sample size of 210 household families surveyed in the area was guaranteed in the study.

(iv) Likert - the scale used in this study to measure survey questions with the following survey level: (Level 5): Very unimportant; (Level 4): Not important; (Level 3): Normal; (Level 2): Important; (Level 1): Very important.

(v) After data collection, SPSS 22.0 was used to analyze the factors affecting women's role in the economic development of rural household families. In particular, Cronbach Alpha has been used to evaluate the reliability of variables; The variance inflation factor and Tolerance (Thang \& Huan, 2011; Morrisson, 2004) are used to check the validity of the research model.

\section{Results and Discussion}

\subsection{Descriptive Statistics}

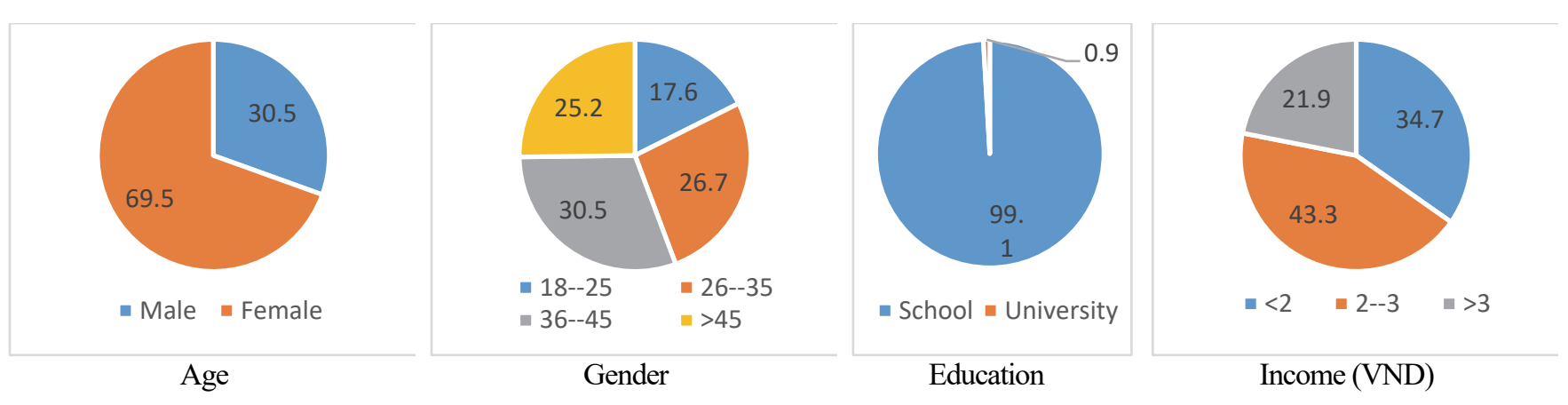

Fig. 2. The sample description of survey participants

Among totally 210 participants, there are $30.5 \%$ of men and $69.5 \%$ of women by gender; $17.6 \%$ participants were $18-25$ years old, $26.7 \%$ participants were $26-35$ years old, $30.5 \%$ participants were $36-45$ years old and $25.2 \%$ participants were $46-60$ years old by age; $4.3 \%$ participants were at illiteracy, $32.4 \%$ participants were at elementary school level, $38.6 \%$ participants were at secondary school level, $23.8 \%$ participants were at high school level and $1.0 \%$ participants were at immediate and college level, $0 \%$ participant was at tertiary education level and postgraduate level; $34.7 \%$ participants had average income less than or equal to 2 million VND, $43.3 \%$ participants had an average income of 2-3 million VND, 21.9\% participants had an average income of over 3 million VND by the average income.

\subsection{Testing Cronbach's Alpha}

Factors affecting the role of women in household economic development are measured by Cronbach's Alpha with a coefficient of 0.782 . No Cronbach's Alpha if item deleted exceeds it to meet the reliability requirement.

\section{Table 1}

Results of Cronbach's Alpha Testing of Attributes

\begin{tabular}{lcccc}
\hline & $\begin{array}{c}\text { Scale Mean if Item } \\
\text { Deleted }\end{array}$ & $\begin{array}{c}\text { Scale Variance if Item } \\
\text { Deleted }\end{array}$ & $\begin{array}{c}\text { Corrected Item-Total } \\
\text { Correlation }\end{array}$ & $\begin{array}{c}\text { Cronbach's Alpha if } \\
\text { Item Deleted }\end{array}$ \\
\hline SP (Social policies) & 7.03 & 7.195 & .320 & .750 \\
E (Education) & 6.55 & 4.469 & .405 & .692 \\
GI (Gender inequality) & 6.68 & 5.931 & .320 & .729 \\
H (Health) & 6.50 & 4.395 & .414 & .684 \\
Al (Access to information) & 6.73 & 6.093 & .445 & .716 \\
\hline
\end{tabular}


(Source: The survey data of the study)

Apart from it, the test results in Table 1 show that the properties of the dependent variables have Alpha coefficient of Cronbach's greater than 0.6 and smaller than the general Alpha coefficient of Cronbach. The correlation coefficient of all attributes is greater than 0.3 . Therefore, all properties of the dependent variables are statistically significant (Nguyen \& Do, 2020; Nunnally, 1978).

\subsection{Factors affecting women's role in the economic development of rural household families in Thanh Hoa province}

With the collected data, the authors used the Binary Logistic regression model to analyze the correlation between the independent and dependent variables. One of the necessary conditions for analyzing the next steps of multivariate regression is that the independent variable must be correlated with the dependent variable. Without correlation, the independent variable is excluded from the regression analysis. Therefore, before performing regression analysis, the authors checked Pearson's correlation coefficient to check the linear relationship between the independent and dependent variables. After a general evaluation of the correlation analysis results, we have found that the variables related to sig $<0.01$ which will be included in the model to explain the dependent variable (no case of multi-plus. because the variance inflation factor $<2$ and Tolerance is greater than 0.5) (Thang \& Huan, 2011).

Table 2

Correlative matrix between variables

\begin{tabular}{|c|c|c|c|c|c|c|c|}
\hline \multicolumn{2}{|c|}{ Correlations } & SP & $\mathrm{E}$ & GI & $\mathrm{H}$ & $\mathrm{Al}$ & $\begin{array}{c}\text { The role of women in } \\
\text { household economic } \\
\text { development }\end{array}$ \\
\hline \multirow[t]{3}{*}{ SP } & Pearson Correlation & 1 & -.036 & -.051 & -.036 & .085 & $.258^{* *}$ \\
\hline & Sig. (2-tailed) & & .106 & .166 & .102 & .221 & .000 \\
\hline & $\mathrm{N}$ & 210 & 210 & 210 & 210 & 210 & 210 \\
\hline \multirow[t]{3}{*}{$\mathrm{E}$} & Pearson Correlation & -.036 & 1 & .087 & $.078^{* *}$ & .061 & $.273^{* *}$ \\
\hline & Sig. (2-tailed) & .106 & & .210 & .000 & .376 & .000 \\
\hline & $\mathrm{N}$ & 210 & 210 & 210 & 210 & 210 & 210 \\
\hline \multirow[t]{3}{*}{ GI } & Pearson Correlation & -.051 & .087 & 1 & .123 & .114 & .013 \\
\hline & Sig. (2-tailed) & .166 & .210 & & .075 & .099 & .003 \\
\hline & $\mathrm{N}$ & 210 & 210 & 210 & 210 & 210 & 210 \\
\hline \multirow[t]{3}{*}{$\mathrm{H}$} & Pearson Correlation & -.036 & $.078^{* *}$ & .123 & 1 & .049 & $.257^{* *}$ \\
\hline & Sig. (2-tailed) & .102 & .000 & .075 & & .183 & .000 \\
\hline & $\mathrm{N}$ & 210 & 210 & 210 & 210 & 210 & 210 \\
\hline \multirow[t]{3}{*}{$\mathrm{Al}$} & Pearson Correlation & .085 & .061 & .114 & .049 & 1 & $.192^{* *}$ \\
\hline & Sig. (2-tailed) & .221 & .376 & .099 & .183 & & .005 \\
\hline & $\mathrm{N}$ & 210 & 210 & 210 & 210 & 210 & 210 \\
\hline \multirow{3}{*}{$\begin{array}{l}\text { The role of women in } \\
\text { household economic } \\
\text { development }\end{array}$} & Pearson Correlation & $.258^{* *}$ & $.273^{* *}$ & .013 & $.257^{* *}$ & $.192^{* *}$ & 1 \\
\hline & Sig. (2-tailed) & .000 & .000 & .003 & .000 & .005 & \\
\hline & $\mathrm{N}$ & 210 & 210 & 210 & 210 & 210 & 210 \\
\hline
\end{tabular}

(Statistical significance level: ${ }^{*} p<0,1 * * p<0,05 * * * p<0,01$ )

(Source: The survey data of the study)

Table 3 presents the results for binary logistic regression as follows:

Table 3

Results for binary logistic regression model

\begin{tabular}{|c|c|c|c|c|c|c|c|c|}
\hline \multirow[b]{2}{*}{ Variables } & \multirow[b]{2}{*}{$\mathrm{B}$} & \multirow[b]{2}{*}{ S.E. } & \multirow[b]{2}{*}{ Wald } & \multirow[b]{2}{*}{ df } & \multirow[b]{2}{*}{ Sig. } & \multirow[b]{2}{*}{$\operatorname{Exp}(B)$} & \multicolumn{2}{|c|}{ 95\% C.I.for EXP(B) } \\
\hline & & & & & & & Lower & Upper \\
\hline SP & .814 & .223 & 13.379 & 1 & .000 & 2.257 & 1.459 & 3.492 \\
\hline $\mathrm{E}$ & .479 & .365 & 1.727 & 1 & .004 & 1.615 & .790 & 3.302 \\
\hline GI & .201 & .165 & 1.490 & 1 & .002 & 1.223 & .885 & 1.690 \\
\hline $\mathrm{H}$ & .208 & .373 & .309 & 1 & .005 & 1.231 & .592 & 2.559 \\
\hline AI & .401 & .166 & 5.809 & 1 & .000 & 1.493 & 1.078 & 2.069 \\
\hline Constant & -5.176 & .781 & 43.894 & 1 & .000 & .006 & & \\
\hline
\end{tabular}

(Statistical significance level: $* p<0.1 * * p<0.05 * * * p<0.01$ )

Observation Number 210

Prob $>\mathrm{Chi}^{2} \quad 0.006$

Loglikelihood $\quad 163.793^{\mathrm{a}}$

Pseudo $\mathrm{R}^{2} \quad 25.2 \% \quad$ (Source: The survey data of the study)

Based on the results in Table 3, the Chi-squared test with sig value $=0.006<0.05$ shows the overall fit of the model and the factors in the model affecting women's role in the economic development of rural household families. In addition, the small value Loglikelihood $=163,793$ and the high probability of the model $(83.8 \%)$ shows the good fit of the analytical model. Pseudo $\mathrm{R}^{2}=25.2 \%$ indicates that the independent variables in the model can explain $21.5 \%$ of the variation of the dependent 
variable according to the variation of the independent variable in the model. With this result, the logistic regression model is presented as follows:

$\operatorname{Logit}(\mathrm{P} / \mathrm{Yi}=1 / \mathrm{Xi}=\mathrm{xi})=-5.176+0.814 \times \mathrm{SP}+0.479 \times \mathrm{E}+0.201 \times \mathrm{GI}+0.208 \times \mathrm{H}+0.401 \times \mathrm{AI}$

\subsection{Exploratory Factor Analysis (EFA)}

The authors conducted exploratory factor analysis (EFA) and Varimax analysis of 5 observed independent variables. Table 4 shows the result of the EFA as $0.5<\mathrm{KMO}=0.603<1$. Sig. $=0.000<0.05$ that means that all variables are related to each other.

Table 4

KMO and Bartlett's Test

Kaiser-Meyer-Olkin Measure of Sampling Adequacy.

Bartlett's Test of Sphericity Approx. Chi-Square

Df

Sig.

(Source: The survey data of the study)

The results of the Rotated Component Matrix table also show that all variables reach values greater than 0.5 . This proves that the factor analysis of the research data is appropriate. Through the EFA model, we have found a number of factors that have a strong impact on women's role in the economic development of rural household families, namely: Access to Information, Gender Inequality and Social Policy.

\section{Conclusions and recommendations}

Based on the regression results, some conclusions and recommendations are given to contribute to enhancing women's role in the economic development of rural household families in Trieu Son district, Thanh Hoa province, Vietnam as follows:

There are many factors such as educational level, health, social policy, access to information, and gender inequality, etc. influencing women's role in the economic development of rural household families. In particular, access to information is a basic factor that makes women have insufficient basic knowledge which are reuired neccessarily to production. The lack of opportunities for women to access information on production knowledge partly comes from men's excessive control of resources that significantly prevent many women from gaining information sources from training, propaganda and learning sessions. Thus, women's role is quite important and must be much concerned.

\section{Firstly, the role of local authorities}

It is ncessary to strengthen communication and advocacy on the media and other forms of local activities on women's role, the guidelines and policies of the Party and government on the equality between men and women in economy, life and society. Currently, it is necessary to change the perception of people, communities and husbands about women's role. This is an important premise to put the provisions of the Gender Equality Law into practice in life and to ensure the effective implementation of the law on gender equality.

It is important to encourag women to promote their self-study capacity and raise awareness about poverty reduction, health care and occupational skills. Paying attention to fostering and raising qualifications, facilitating the promotion of the capacity of female staff who are working in state organs and mass organizations at all levels to promote the status of women in social activities. Gradually transforming the local economic structure by strongly developing industries and rural services; creating more non-agricultural jobs for women; creating conditions for increasing family incomes with non-agricultural sources; reducing women's economic burdens and worries.

\section{Secondly, the role of families}

The community must improve awareness for family members, especially women, about the knowledge to organize family life, raise and take care of children; encouraging family members to share activities of labor, familiy and emotional life.

We also recommend building models of happy families with equality between husband and wife without male chauvinism. Husband and wife have compromise on the housework. They need to mobilizie and create conditions for women to regularly participate in activities and meetings of mass organizations, to study and to have chance to learn from books, newspapers, the media, etc. to improve their knowledge level; creating an environment for them to promote and affirm their role in the family and society. 
It is very important for the women to participate in the economic development of household families. If a woman is aware of her important role, she can enhance her role in the family and in the society. At the same time, an active and proactive woman will both perform well social work and keep a happy family.

\section{References}

Basu, A. M., \& Basu, K. (1991). Women's economic roles and child survival: the case of India. Health Transition Review, 1(1), 83-103.

Ba, H., Thu, P., Chi, T., Thanh, H., \& Huy, C. (2020). Solutions to attract investment capital for tourism development: Evidence from Vietnam economy. Accounting, 6(2), 209-214.

Baarhmitash, R. (2000). The role of women in economic development case study of Taiwan, Indonesia and Vietnam. Montreal, Quebec: University McGill.

Bayeh, E. (2016). The role of empowering women and achieving gender equality to the sustainable development of Ethiopia. Pacific Science Review B: Humanities and Social Sciences , 2(1), 37-42.

Beneria, L. S. (1981). Accumulation, Reproduction, and Women's Role in Economic Development: Boserup Revisited. Journal of Women in Culture and Society , 7(2), 279 - 298.

Boserup, E. (1970). Womens Role in Economic Development. New York: New York: St. Martin's Press.

Fabiyi, E. D. (2007). Role of women in agricultural development and their constraints: a case study of Biliri Local Government Area, Gombe State, Nigeria. Pakistan Journal of Nutrition , 6(6), 676 - 680.

Madina Junussova, M. I. (2019). The Role of Women in the Economic Development of Afghanistan. Tajikistan: Institute of Public Policy and Administration, University of Central Asia.

Morrisson, C. J. (2004). The impact of social institutions on the economic role of women in developing countries. OECD Development Centre Working.

Nunnally, J. (1978). Psychometric Theory. New York: McGraw-Hill.

Nguyen, D \& Do, D. (2020). The impact of equity in FDI firms on accountants' loyalty: Application of equity theory and creative application in economics sociological knowledge. Accounting , 6(2), 215-220.

Quyen, D. H., \& Nguyen, T. L. (2006). A survey on women's role in agriculture and rural areas in Nghia Hiep commune, Yen My District, Hung Yen province. Hanoi: Agricultural University.

Quynh, N. N. (2009). The role of women in household economic development in rural areas in Ninh Binh province. Ninh Bình: Ninh Binh Women's Union.

Thang, D. V., \& Huan, P. T. (2011). SPSS curriculum for students of social sciences and humanities. Ho Chi Minh: National University Publishing House, Ho Chi Minh City.

Trieu Son, D. (2011). Report on population in Trieu Son district in the period 2006-2010. Thanh Hoa: Trieu Son District.

Van, V. T. (2009). The role of rural women in household economic development in Phu Luong district, Thai Nguyen province. Thai Nguyen: Thai Nguyen University.

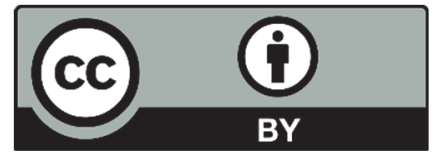

(C) 2020 by the authors; licensee Growing Science, Canada. This is an open access article distributed under the terms and conditions of the Creative Commons Attribution (CC-BY) license (http://creativecommons.org/licenses/by/4.0/). 